Original Article

\title{
DRUMSTICK MUCILAGE MICROSPHERES FOR CONTROLLED RELEASE OF LAMIVUDINE: DESIGN, OPTIMIZATION AND IN VITRO EVALUATION
}

\author{
SANTOSH GADA* ${ }^{*}$, ANANDKUMAR Y.2 ${ }^{2}$ C. MALLIKARJUN SETTY 3
}

1JNTU Hyderabad and KCT College of Pharmacy, Gulbarga, Karnataka India, ${ }^{2}$ Department of Pharmaceutics, V L College of Pharmacy, Raichur, Karnataka, India, ${ }^{3}$ Department of Pharmaceutics, Oxford College of Pharmacy, Bengaluru, Karnataka, India Email: gadasantosh@yahoo.co.in

Received: 14 Jun 2018 Revised and Accepted: 15 Feb 2019

\section{ABSTRACT}

Objective: The objective of this study was to design and evaluate controlled release mucoadhesive microspheres of lamivudine using mucoadhesive polymers and mucilage.

Methods: Mucoadhesive microspheres of lamivudine were formulated by ionic gelation method. The response surface methodology was adapted for optimization of formulation using central composite design (CCD) for two factors at three levels each was employed to study the effect of independent variables, Sodium alginate-drumstick mucilage $\left(\mathrm{X}_{1}\right)$ and calcium chloride $\left(\mathrm{CaCl}_{2}\right)$ concentration $\left(\mathrm{X}_{2}\right)$ on dependent variables, namely drug encapsulation efficiency (DEE) and particle size (PS). Optimized drumstick mucilage mucoadhesive microspheres of lamivudine were obtained by using numerical optimization of desirability approach. The observed microspheres were coincided well with the predicted values by the experimental design.

Results: The microspheres formed were spherical in shape, and Particle size (PS) ranged between $681.63-941.57 \mu$ m. Drug encapsulation efficiency (DEE) was ranged between 69.63-94.56 \%. The drug release for an optimized formulation was $96.58 \%$. The mechanism of drug release from microspheres followed Korsemeyer's-Peppas and exponential ' $n$ ' value was greater than 0.45 , indicating the drug release was non-fickian i.e., swelling followed by erosion mechanism.

Conclusion: This work suggests that mucoadhesive microspheres, an effective drug delivery system for lamivudine, can be prepared using drumstick mucilage in improving the bioavailability of the drug.

Keywords: Lamivudine, Optimization, Drumstick, Sodium Alginate, Model fitting

(C) 2019 The Authors. Published by Innovare Academic Sciences Pvt Ltd. This is an open access article under the CC BY license (http://creativecommons.org/licenses/by/4.0/) DOI: http://dx.doi.org/10.22159/ijpps.2019v11i4.30733

\section{INTRODUCTION}

The main goal of drug delivery systems is to achieve a desired concentration of the drug in blood or tissue, which is therapeutically effective and non-toxic for a prolonged period. The most preferable route of drug delivery is oral drug delivery, due to its ease of administration, patient compliance, and flexibility in the formulations. The major objective of oral controlled drug delivery system is to deliver drugs for a longer period of time to achieve better bioavailability, which should be predictable and reproducible [1].

The mucoadhesive polymer containing oral drug delivery systems has the capacity to prolong the residence time of drugs at the absorption site and facilitate intimate contact with an underlying absorptive surface to enhance bioavailability [2]. Polymers used in the mucoadhesive formulations include natural, semi-synthetic, and synthetic ones. In recent years, a growing interest has been identified in the development of natural polymer-based drug delivery systems due to their biodegradability, biocompatibility, aqueous solubility, swelling ability, easy availability, and costeffectiveness [3]. Amongst various natural polymers, alginates have been widely used in the development of drug delivery applications [4-7]. It is composed of linear copolymers of two monomeric units, that is, $\alpha$-D-mannuronic acid and $\alpha$-L-guluronic acid [8]. Sodium alginate undergoes ionotropic-gelation by $\mathrm{Ca} 2+$ to form calcium alginate due to an ionic interaction between carboxylic acid groups of alginate chain and $\mathrm{Ca} 2+[9]$. Sodium alginate has mucoadhesive property; however, the cross-linked alginates are usually fragile [10, 11]. Therefore, the blending of different mucoadhesive polymers is one of the most popular approaches to formulate ionotropically cross-linked alginate-based mucoadhesive spheres [10, 12, 13]. Again, blending with suitable polymers, may improve the drug encapsulation, which is found comparatively lower in alginate-based microspheres prepared by ionotropic-gelation method [7].
Drumstick is a rich source of the polysaccharide galactomannan. Drumstick is a source of saponins such as diosgenin, yamogenin, gitogenin, tigogenin, and neotigogens, other bioactive constituents of moringa include mucilage, volatile oils, and alkaloids such as choline and trigonelline. Mucilage is obtained from stem and pods of moringa oleifera (family: Moringaceae). The mucilage is a polyuronide constituting of arabinose, galactose, and glucuronic acid in the proportion of 10:7:2, rhamnose present in traces. The gelling concentration of the mucilage was found to lie between 7 and $8.5 \% \mathrm{w} / \mathrm{v}$. The mucilage exhibited pseudoplastic flow and viscosity were found to be ideal for topical application [14], binding property and release retardant property [15].

Lamivudine is a synthetic nucleoside analog that is being increasingly used as the core of an antiretroviral regimen for the treatment of HIV infection $[16,17]$. In vivo, nucleoside analogs are phosphorylated intracellularly by endogenous kinases to putatively active $5^{\prime}$-triphosphate (3TC-TP) derivatives that prevent HIV replication by competitively inhibiting viral reverse transcriptase and terminating proviral DNA chain extension [18-20]. Lamivudine is rapidly absorbed after oral administration with an absolute bioavailability of $86 \% \pm 16 \%$, peak serum concentration of lamivudine (Cmax) of $1.5 \pm 0.5 \mu \mathrm{g} / \mathrm{ml}$ and mean elimination half-life $(\mathrm{t} 1 / 2)$ of 5 to $\mathrm{h}$, thus necessitating frequent administration to maintain constant therapeutic drug levels [21].

Therefore, it would be beneficial to develop a mucoadhesive system of lamivudine using drumstick-alginate for oral use, which might facilitate an intimate contact with the mucous membranes (i.e., mucoadhesion or bioadhesion) and thus the release of lamivudine at a controlled rate over an extended period to maximize the therapeutic effect.

In the development of any pharmaceutical formulation, an important issue is to design a formulation with optimized quality in a short 
time period and a minimum number of trials [22, 23]. Traditionally, research formulators produce formulation by changing only one variable at a time while keeping other variables fixed. This classical method is laborious and time-consuming. Therefore, it is essential to understand the influence of formulation ingredients or factors on the properties of formulations with a minimal number of experimental trials and subsequent selection of formulation ingredients or factors to develop an optimized formulation using established statistical tools [6, 24-26]. Factorial designs, where all the factors are studied in all possible combinations, are considered the most efficient in estimating the influence of individual factors and their interactions performing minimum numbers of experiments [27]. A computer-aided optimization technique based on $3^{2}$ (two factors and three levels) factorial design and response surface methodology was employed to investigate the effects of two independent process variables (ingredients or factors), i.e., sodium alginate-drumstick mucilage ratio and concentration of $\mathrm{CaCl}_{2}$ on the properties of ionotropically gelled drumstick mucilage-alginate mucoadhesive microspheres of lamivudine such as DEE and PS of microsphere.

\section{MATERIALS AND METHODS}

\section{Materials}

Lamivudine obtained as gift sample from Hetero Drugs Private Ltd, Sodium alginate and calcium chloride were procured from yarrow chemicals and SD fine chemicals Mumbai respectively. Drumstick pods were procured from local market. All other reagents used were of analytical grades and double distilled water was used throughout the studies.

\section{Method}

\section{Isolation of drumstick powder mucilage}

Mucilage was isolated from the pods of Moringa oleifera Lam. (500g) by dissolving it in distilled water. Further, it was boiled for $1 \mathrm{~h}$ under reflux with occasional stirring and kept aside for $2 \mathrm{~h}$ for the release of mucilage into water then filtered. The filtrate was precipitated out with ethanol in crude form. The precipitated material was filtered through a muslin bag into conical flask and marc is squeezed well in order to remove the mucilage completely, in between hot distilled water $(25 \mathrm{ml})$ was added through the sides of muslin bag. The aqueous filtrate is concentrated to $1 / 3 \mathrm{rd}$ of its volume; mucilage is precipitated by adding an equal volume of ethanol. The obtained precipitate is settled by keeping in a refrigerator for overnight. After complete settling of the precipitate, it was filtered and dried the residue at $37{ }^{\circ} \mathrm{C}$. The obtained dried powder was reduced to fine powder and passes through $120 \#$ and subjected for identification test to confirm its identity. The prepared drumstick mucilage powder was stored in desiccators for further study [28, 29].

Preparation of drumstick mucilage-alginate mucoadhesive microspheres of lamivudine by orifice ionic gelation method

The drumstick mucilage-alginate mucoadhesive microspheres of lamivudine were prepared by the ionotropic-gelation technique using $\mathrm{CaCl}_{2}$ as cross-linker. Sodium alginate and drumstick mucilage aqueous dispersions were prepared separately using distilled water. These dispersions were mixed well with stirring for $15 \mathrm{~min}$. Lamivudine was added to the dispersion mixture, the ratio of drug to polymer was maintained 1: 2 in all formulations. The resulting dispersion was then added via a 21-gauge needle into $100 \mathrm{ml}$ of $\mathrm{CaCl}_{2}$ solution. The added droplets were retained in the $\mathrm{CaCl}_{2}$ solution for $15 \mathrm{~min}$ to complete the curing reaction and to produce rigid spheres. The wet spheres were collected by decantation and washed two times with distilled water and dried at $37{ }^{\circ} \mathrm{C}$ for $24 \mathrm{~h}$. The dried drumstick mucilage-alginate mucoadhesive microspheres of lamivudine were stored in desiccators until used [30].

\section{Experimental design for optimization}

A $3^{2}$ factorial design was employed for optimization with sodium alginate: drumstick mucilage $\left(\mathrm{X}_{1}\right)$ and concentration of $\mathrm{CaCl}_{2}\left(\mathrm{x}_{2}\right)$ as selected independent variables, which were varied at three levels, low $(-1)$, medium $(0)$, and high $(+1)$. The DEE, $(\%)$ and PS $(\mu \mathrm{m})$ were used as dependent variables (responses). Design-Expert Demo Version 11 software (Stat-Ease In C., USA) was used for the generation and evaluation of the statistical experimental design. The batches were prepared as per design and investigated responses, i.e., DEE and PS were shown in table 1 . The effects of independent variables upon the all measured responses were modeled using the following quadratic mathematical model generated by $3^{2}$ factorial designs [6].

$$
\mathrm{Y}=\mathrm{b}_{0}+\mathrm{b}_{1} \mathrm{X}_{1}+\mathrm{b}_{2} \mathrm{X}_{2}+\mathrm{b}_{3} \mathrm{X}_{1} \mathrm{X}_{2}+\mathrm{b}_{4} \mathrm{X}_{1}{ }^{2}+\mathrm{b}_{5} \mathrm{X}_{2}{ }^{2}
$$

Where $Y$ is the response, $b_{0}$ is the intercept, and $b_{1}, b_{2}, b_{3}, b_{4}, b_{5}$ are regression coefficients. $X_{1}$ and $X_{2}$ are individual effects. $X_{1}{ }^{2}$ and $X_{2}{ }^{2}$ are model quadratic effects; $\mathrm{X}_{1} \mathrm{X}_{2}$ is the interaction effects. One-way ANOVA was applied to estimate the significance $(\mathrm{P}<0.05)$ of generated models. Individual response parameters were evaluated using the $F$-test. The response surface methodology was applied to analyze the effect of independent factors (SA: Drumstick mucilage and $\mathrm{CaCl}_{2}$ ) on the measured responses (DEE and PS).

Table 1: Plan of $3^{2}$ factorial designs with responses for different drumstick mucilage-alginate mucoadhesive microspheres of lamivudine

\begin{tabular}{|c|c|c|c|c|}
\hline \multirow[t]{2}{*}{ Batch code } & \multicolumn{2}{|l|}{ Normal input variables } & \multicolumn{2}{|c|}{ Responses } \\
\hline & Sodium alginate: drumstick mucilage $\left(X_{1}\right)$ & $\mathrm{CaCl}_{2}(\%)\left(\mathrm{X}_{2}\right)$ & DEE (\%) & PS $(\mu \mathrm{m})$ \\
\hline F-1 & 4 & 5 & 74.89 & 885.12 \\
\hline F-2 & 1 & 7.5 & 79.05 & 779.36 \\
\hline F-3 & 4 & 10 & 69.63 & 941.57 \\
\hline F-4 & 1 & 5 & 85.26 & 749.63 \\
\hline F-5 & 4 & 7.5 & 79.59 & 812.85 \\
\hline F-6 & 2.5 & 10 & 82.79 & 790.86 \\
\hline F-7 & 2.5 & 7.5 & 94.56 & 681.63 \\
\hline F-8 & 2.5 & 5 & 73.82 & 844.39 \\
\hline F-9 & 1 & 10 & 87.62 & 712.76 \\
\hline
\end{tabular}

\section{Evaluation}

\section{Production yield}

All the batches of dried microspheres were accurately weighed separately and percentage yield is calculated by using the given equation.

$$
\text { Production yeild }=\frac{\text { Practicalweight }}{\text { Theoretical weight }(\text { polymer }+ \text { drug })} \times 100
$$

\section{Determination of DEE (\%)}

Accurately weighed, $100 \mathrm{mg}$ of microspheres were taken and were crushed using pestle and mortar. The crushed powders of drugcontaining microspheres were placed in $500 \mathrm{ml}$ of phosphate buffer
$\mathrm{pH} 7.4$ and kept for $24 \mathrm{~h}$ with occasional shaking at $37 \pm 0.5^{\circ} \mathrm{C}$. After the stipulated time, polymer debris formed after the disintegration of microspheres was removed by filtration. The drug content in the filtrate was determined using a UV-VIS spectrophotometer (Shimadzu, Japan) at $271 \mathrm{~nm}$. The DEE of microspheres was calculated using the following formula:

$$
\text { Encapsulation effeciency }=\frac{\text { Actual amount of drug encapsulated }}{\text { Theoretical drug content }} \times 100
$$

\section{PS measurement}

PS and size distribution of mucoadhesive microspheres of lamivudine were measured by sieve analysis using mechanical 
sieve shaker. Different sizes in a batch are separated by sieve using a range of standard sieves 10/22, 22/44 and the amounts retained on different sieves were weighed. The sizes of the microspheres were determined by carrying out studies in triplicate and its average size is calculated by using the given following equation.

$$
\mathrm{D}_{\mathrm{AvE}}=\frac{\Sigma \mathrm{Xifi}}{\mathrm{fi}}
$$

Where, $\mathrm{X}_{\mathrm{i}}$-Mean size range;

$\mathrm{f}_{\mathrm{i}}$-Percentage microspheres retained on the smaller sieve range.

\section{Surface morphology studies of microspheres by scanning} electron microscopy

The PS, shape and surface morphology of optimized mucoadhesive microspheres were examined by scanning electron microscopy. Mucoadhesive microspheres were fixed on aluminum studs and coated with gold using a sputter coater SC 502, under vacuum [0.1 $\mathrm{mm} \mathrm{Hg]} \mathrm{and} \mathrm{are} \mathrm{analyzed} \mathrm{using-Model} \mathrm{JSM-840} \mathrm{A,} \mathrm{Joel.} \mathrm{Japan.}$

\section{In vitro drug release studies}

The release of optimized formulation drumstick mucilage-alginate microspheres of lamivudine and marketed tablet viz., Lamivir were tested using a dissolution test apparatus USP-I. The baskets were covered with cloth to prevent microspheres to escape out. The dissolution rates were measured at $37 \pm 1^{\circ} \mathrm{C}$ at $50 \mathrm{rpm}$ speed.

Drumstick mucilage-alginate microspheres of lamivudine equivalent to $50 \mathrm{mg}$ of lamivudine were taken in $900 \mathrm{ml}$ of dissolution medium (phosphate buffer, $\mathrm{pH}$ 7.4). An amount of $5 \mathrm{ml}$ of aliquots was collected at regular time intervals and the same amount of fresh phosphate buffer $\mathrm{pH} 7.4$ medium was replaced into the dissolution vessel to maintain sink condition throughout the experiment. The collected aliquots were filtered and suitably diluted to determine absorbance using a UV-VIS spectrophotometer (Shimadzu, Japan) at $271 \mathrm{~nm}$ against a blank (phosphate buffer, $\mathrm{pH} 7.4$ ). In order to predict and correlate the in vitro release behavior of lamivudine from optimized formulation drumstick mucilage-alginate microspheres and marketed tablet Lamivir, data were fitted into a suitable mathematical model. The studies were carried out in triplicate. The in vitro dissolution data were tabulated and computed by using dissolution software viz., PCP DISSO V3.0.

Table 2: Report of ANOVA of responses for DEE and PS

\begin{tabular}{|c|c|c|c|c|c|}
\hline Source & Sum squares & df & Mean square & F value & P value probe $>F$ \\
\hline \multicolumn{6}{|c|}{ For DEE(\%) } \\
\hline Model & 472.54 & 5 & 94.51 & 2583.27 & $<0.0001$ \\
\hline $\mathrm{X}_{1}$ & 171.74 & 1 & 171.74 & 4694.23 & $<0.0001$ \\
\hline$X_{2}$ & 293.02 & 1 & 293.02 & 8009.48 & $<0.0001$ \\
\hline $\mathrm{X}_{1} \mathrm{X}_{2}$ & 0.8190 & 1 & 0.8190 & 22.39 & 0.0179 \\
\hline $\mathrm{X}^{2}{ }_{1}$ & 1.83 & 1 & 1.83 & 50.03 & 0.0058 \\
\hline $\mathrm{X}^{2}{ }_{2}$ & 5.13 & 1 & 5.13 & 140.24 & 0.0013 \\
\hline \multicolumn{6}{|c|}{ For PS $(\mu \mathrm{m})$} \\
\hline Model & 53928.47 & 5 & 10785.69 & 198.27 & 0.0006 \\
\hline$X_{1}$ & 23242.91 & 1 & 23242.91 & 427.28 & 0.0002 \\
\hline $\mathrm{X}_{2}$ & 28505.31 & 1 & 28505.31 & 524.02 & 0.0002 \\
\hline $\mathrm{X}_{1} \mathrm{X}_{2}$ & 94.97 & 1 & 94.97 & 1.75 & 0.2781 \\
\hline $\mathrm{X}^{2}{ }_{1}$ & 1976.95 & 1 & 1976.95 & 36.34 & 0.0091 \\
\hline $\mathrm{X}^{2}{ }_{2}$ & 108.34 & 1 & 108.34 & 1.99 & 0.2530 \\
\hline
\end{tabular}

\section{RESULTS AND DISCUSSION}

Mucilage was isolated from drumstick (Moringa oleifera) pod and the average yield of mucilage was found $5.86 \% \mathrm{w} / \mathrm{w}$. For the $3^{2}$ factorial design, a total of 9 trial formulations were proposed by Design-Expert Demo Version 11 software (Stat-Ease Inc., USA). According to this trial proposal, various drumstick mucilage-alginate microspheres of lamivudine were prepared by ionotropic gelation technique. When various dispersion mixtures containing different polymer-blend (Sodium alginate and Drumstick mucilage) and lamivudine were dropped into the solutions containingCaCl 2 , drumstick mucilage-alginate of lamivudine microspheres were formed instantaneously due to the electrostatic interaction between alginate ions and calcium ions present in the cross-linking solutions. The values of DEE and PS of microspheres, measured for all the formulations reported in table 1 , were fitted in the $3^{2}$ factorial design to get model equations. The Design-Expert Demo Version 11 software (Stat-Ease InC., USA) provided quadratic model equations involving individual main factors and interaction factors for all response parameters. The results of the ANOVA given in table 2, showing these models were significant for all response parameters.

The model equation relating

DEE (\%) $=79.09-5.35 \mathrm{X}_{1}+6.98 \mathrm{X}_{2}-0.4525 \mathrm{X}_{1} \mathrm{X}_{2}+0.9567 \mathrm{X}_{1}^{2}+1.60 \mathrm{X}_{2}^{2}$ (国 ${ }^{2}=$ $0.9908 ; F$ value $=2583.27 ; P<0.05)$.

The model equation relating

PS $(\mu \mathrm{m})=783.74+62.4 \mathrm{X}_{1}-68.93 \mathrm{X}_{2}-4.87 \mathrm{X}_{1} \mathrm{X}_{2}-31.44 \mathrm{X}_{1}{ }^{2}-7.36 \mathrm{X}_{2}{ }_{2}\left(\mathrm{R}^{2}=\right.$ $0.9970 ; F$ value $=198.27 ; \mathrm{P}<0.05)$.

\section{Design-Expert ${ }^{\circledR}$ Software Trial Version}

\section{DEE}

Color points by value of

DEE:

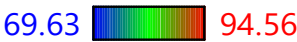

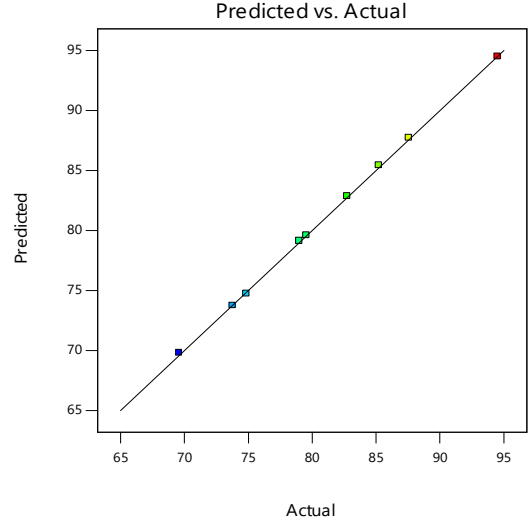

Fig. 1: Linear correlation plot containing DEE (\%) between the actual and the predicted values 
Design-Expert ${ }^{\circledR}$ Software

Trial Version

DEE

Color points by value of

DEE:

$69.63 \longrightarrow 94.56$

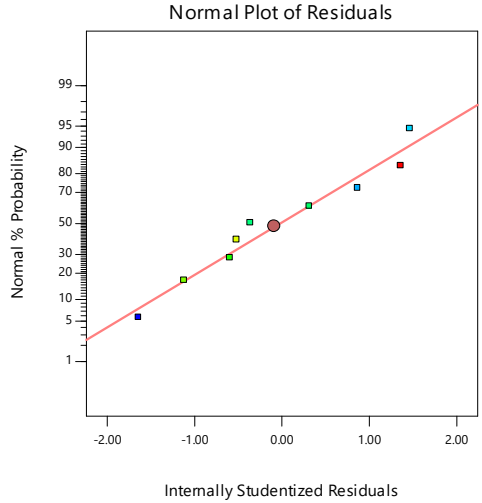

Internally Studentized Residuals

Fig. 2: Normal residual plot containing DEE (\%) showing the scatter of the residuals versus predicted values

The influences of main effects (factors) on responses DEE and PS were further elucidated by response surface methodology. Response surface methodology is a widely proficient approach in the development and optimization of drug delivery devices $[6,9,31]$. Response surface methodology encompasses the generation of model equations of the investigated responses over the experimental domain to determine optimum formulation (s) [32]. The three-dimensional response surface plot is very useful in learning about the main and interaction effects of the independent variables (factors), whereas two-dimensional contour plot gives a

\section{Design-Expert ${ }^{\circledR}$ Software \\ Trial Version}

PS

Color points by value of

PS:

$681.63 \square \square 941.57$ visual representation of values of the response [5]. The threedimensional response surface plot of DEE (fig. 5) shows the increment of DEE with the lowering of sodium alginate-drumstick mucilage $\left(\mathrm{X}_{1}\right)$ and increasing of $\mathrm{CaCl}_{2}$ concentration $\left(\mathrm{X}_{2}\right)$. However, an increase in PS with the increment in sodium alginate-drumstick mucilage $\left(\mathrm{X}_{1}\right)$ and lowering of $\mathrm{CaCl}_{2}$ concentration $\left(\mathrm{X}_{2}\right)$ is shown by the three-dimensional response surface plot containing PS as shown in fig. 7. Contour plots as shown in fig. 6 and 8, showed responses of DEE and PS as nonlinear relationships between in dependable variables.

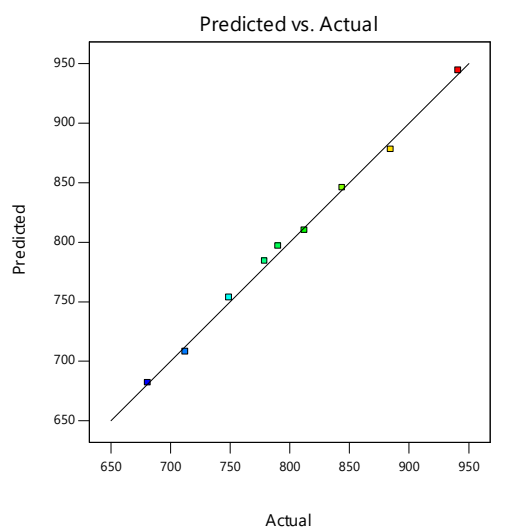

Fig. 3: Linear correlation plot containing PS $(\mu \mathrm{m})$ between the actual and the predicted values

\section{Design-Expert ${ }^{\circledR}$ Software Trial Version}

\section{PS}

Color points by value of

PS:

$681.63 \square \square 41.57$

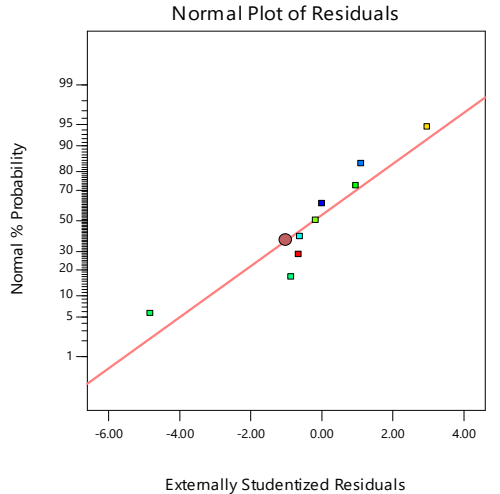

Fig. 4: Normal residual plot containing PS $(\mu \mathrm{m})$ showing the scatter of the residuals versus predicted values

Numerical optimization technique with the desirability approach was used to develop optimized formulations for the desired response (optimum quality). The desirable ranges of the responses DEE targeted to maximum $(90.00 \leq \mathrm{DEE} \leq 100.00 \%)$ and PS minimized to $(650.00 \leq$ Particle size $\leq 750.00 \mu \mathrm{m})$. The optimal values of responses were obtained by numerical analysis using the Design-Expert Demo Version
11 software (Stat-Ease InC., USA) based on the criterion of desirability. The desirability plot showing desirable regression ranges for variable settings of the optimization process was given in fig. 9, and overlay plot showing the region of variable settings of the optimization process was shown in fig. 10. In order to evaluate the optimization capability of these models generated according to the results of $3^{2}$ factorial design, 
optimized drumstick mucilage-alginate microspheres of lamivudine were prepared using one of the variable settings of the optimization process proposed by the design (prediction $\mathrm{R}^{2}=1$ ). The selected variable settings of the optimization process were used for the formulation containing $X_{1}=1.24$ and $X_{2}=9.36$. The optimized microspheres containing lamivudine (F-Optimised) were evaluated for DEE (\%) and PS $(\mu \mathrm{m})$. The results of experiments with predicted responses by the mathematical models and those actually observed for optimized formulation were shown in table 3 . The optimized drumstick-alginate microspheres of lamivudine (F-Optimised) showed DEE of $92.106 \pm 3.96 \%$ and PS $724.68 \mu \mathrm{m} \pm 5.65 \%$ with small error values $(0.125$ and 4.817 resp), indicating that mathematical models obtained from the 3 factorial design were fitted well.
The DEE (\%) of all these drumstick mucilage-alginate microspheres of lamivudine was within the range between $69.63 \pm 1.77$ and $94.56 \pm 4.80 \% \mathrm{w} / \mathrm{w}$ (Tables 1 and 3 ). It was observed that DEE (\%) was increased with the lowering of sodium alginate: drumstick mucilage blend, which may be due to an increase in viscosity of the solution by the addition of drumstick mucilage. This may be due to blocking of drug leaching to the cross-linking solution and the increase of cross-linking by $\mathrm{CaCl}_{2}$.

The average microsphere size of drumstick mucilage-alginate microspheres of lamivudine was within the range of $681.63 \pm 5.06$ to $941.57 \pm 4.12 \mu \mathrm{m}$ (table 1). Increase in the average size of microspheres was found with the increasing proportion of drumstick mucilage with sodium alginate.
Design-Expert ${ }^{\circledR}$ Software

Trial Version

Factor Coding: Actual

DEE (\%)

Design points above predicted value

O Design points below predicted value

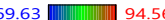

1 $=$ A: Sodium Alginate: Drumstick X2 = B: Calcium Chloride

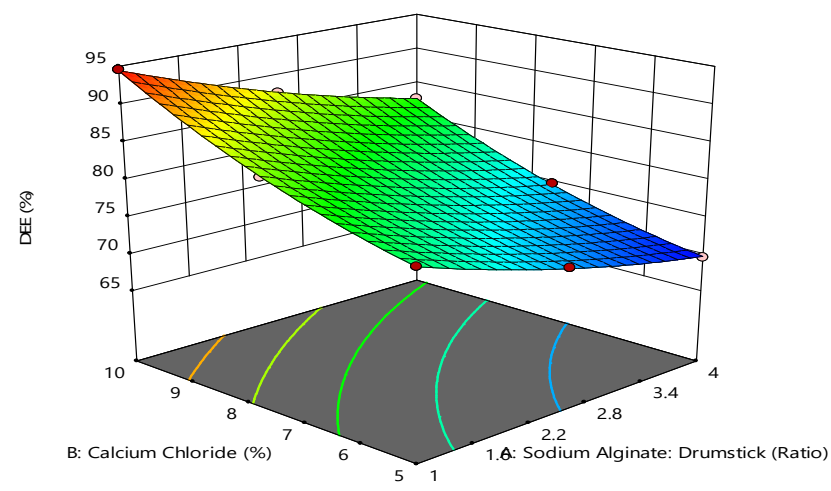

Fig. 5: Response surface plot, showing effect of sodium alginate-drumstick mucilage and concentration of $\mathrm{CaCl}_{2}$ on $\mathrm{DEE}^{-}$

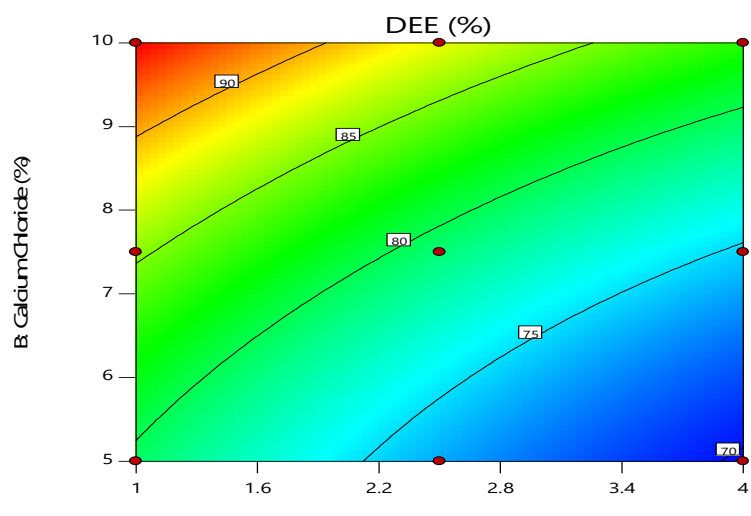

A: Sodium Alginate: Drumstick (Ratio)

Fig. 6: Contour Plots showing, an effect of sodium alginate-drumstick mucilage and concentration of $\mathrm{CaCl}_{2}$ on $\mathrm{DEE}^{-}$

Design-Expert ${ }^{\circledR}$ Software

Trial Version

Factor Coding: Actual

PS $(\mu \mathrm{m})$

Design points above predicted value $681.63 \square 941.57$

$X_{1}=$ A. Sodium Alginate: Drumstick X2 $=$ B: Calcium Chloride

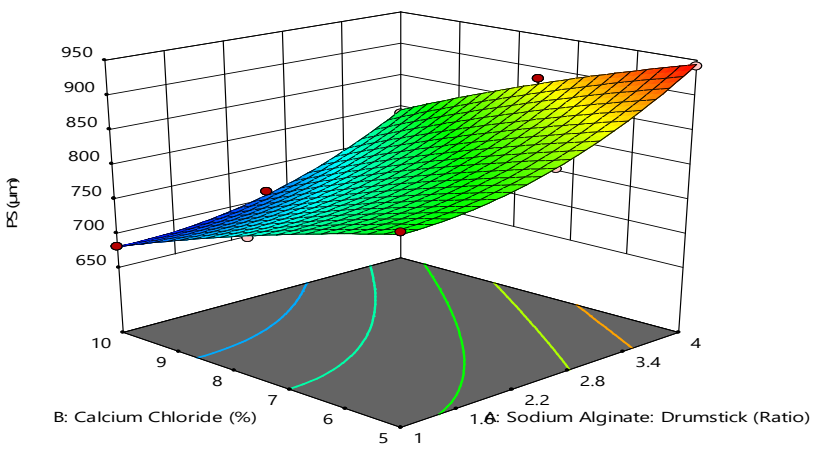

Fig. 7: Response surface plot, showing effect of sodium alginate-drumstick mucilage and concentration of $\mathrm{CaCl}_{2}$ on particle size 
Design-Expert $\otimes^{\circledR}$ Software

Trial Version

Factor Coding: Actual

PS ( $\mu \mathrm{m})$

Design Points

X1 = A: Sodium Alginate: Drumstick X2 = B: Calcium Chloride

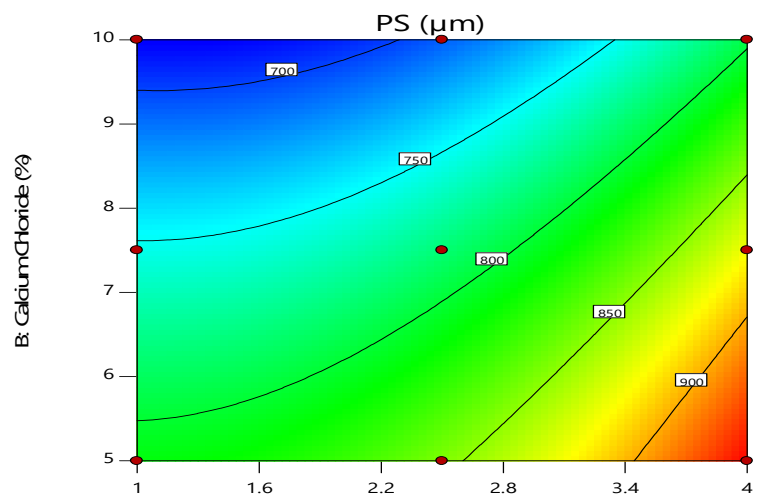

A: Sodium Alginate: Drumstick (Ratio)

Fig. 8: Contour plot showing, the effect of sodium alginate-drumstick mucilage and concentration of $\mathrm{CaCl}_{2}$ on particle size

Table 3: Results of actual and predicted values for DEE and PS responses at optimized conditions

\begin{tabular}{|c|c|c|c|c|}
\hline Batch code & Sodium alginate: drumstick mucilage & $\mathrm{CaCl}_{2} \%$ & DEE\% & PS $(\mu \mathrm{m})$ \\
\hline & & \multicolumn{3}{|c|}{ Actual values } \\
\hline \multirow[t]{3}{*}{ F-Opt } & 1.240 & 9.364 & 90.652 & 701.199 \\
\hline & & & \multicolumn{2}{|c|}{ Predicted values } \\
\hline & & & 92.106 & 724.68 \\
\hline \% Error & & & 0.125 & 4.817 \\
\hline
\end{tabular}

Design-Expert ${ }^{\circledR}$ Software

Trial Version

Factor Coding: Actual

Desirability

Design Points

$\mathrm{X} 1=\mathrm{A}:$ Sodium Alginate: Drumstick X2 $=$ B: Calcium Chloride

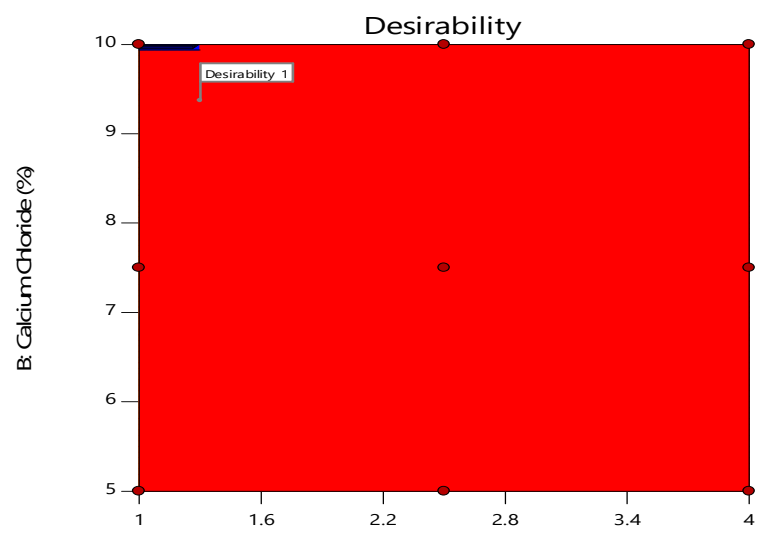

A: Sodium Alginate: Drumstick (Ratio)
Design-Expert ${ }^{\circledR}$ Software

Trial Version

Factor Coding: Actua

Overlay Plot

DEE

StdErr(DEE)

Design Points

X1 = A: Sodium Alginate: Drumstick X2 $=$ B: Calcium Chloride

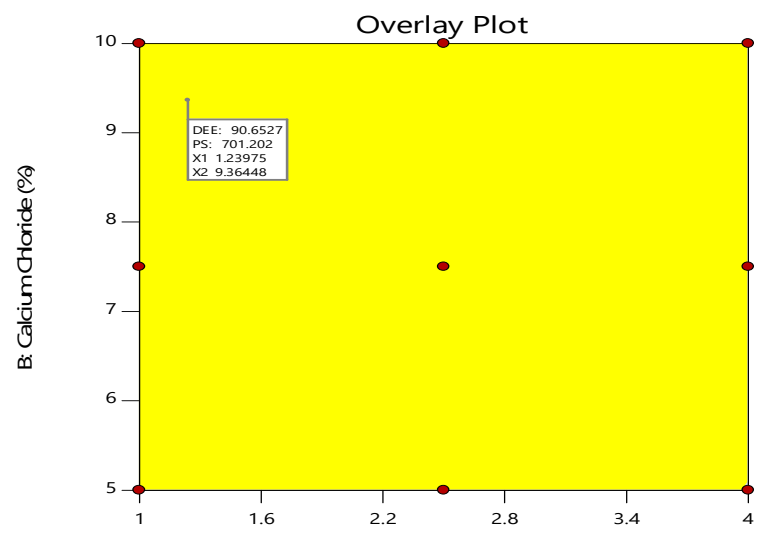

A: Sodium Alginate: Drumstick (Ratio)

Fig. 10: The overlay plot showing the variable settings for the region of process optimization 


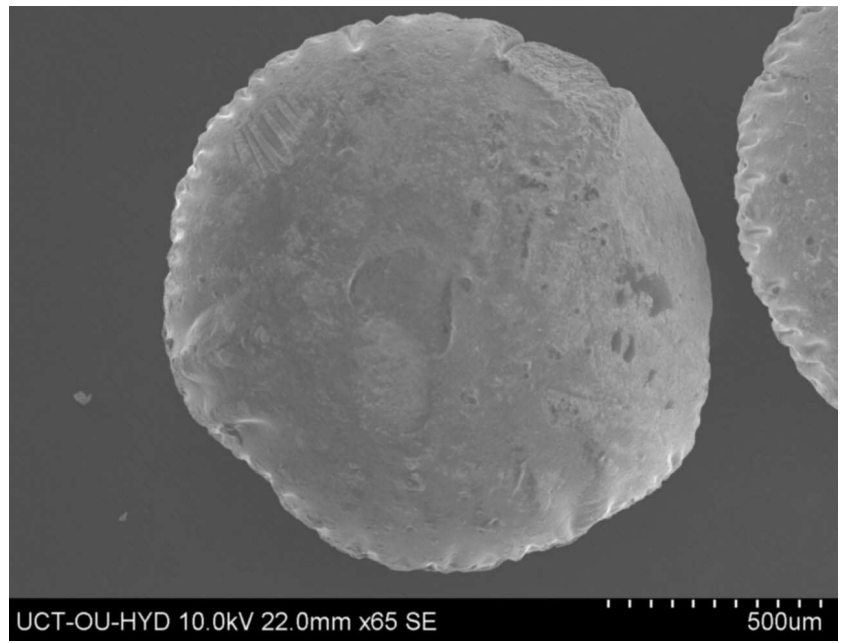

Fig. 11: Scanning electron microphotograph of optimized drumstick mucilage-alginate microspheres of lamivudine (F-0pt)

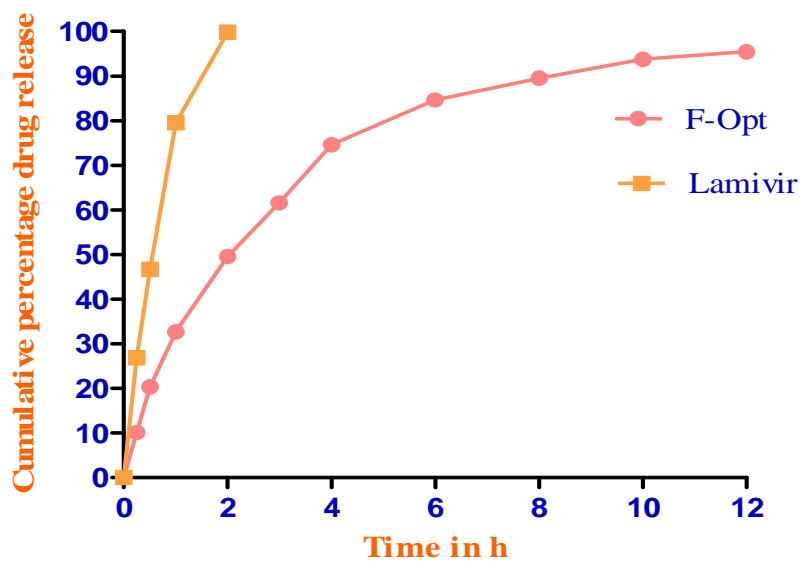

Fig. 12: In vitro comparison plots for the release of lamivudine from both optimized drumstick mucilage-alginate microspheres and marketed lamivir tablet

This could be attributed due to the increase in viscosity of polymer solution with the increased proportion of drumstick mucilage, which increased the droplet size of polymer-blend solutions to the cross-linking solutions during preparation. The surface morphological analysis of drumstick mucilage-alginate microspheres of lamivudine was visualized by scanning electron micrograph as shown in fig. 11. The scanning electron micrograph of these microspheres possessed irregular shape without forming agglomeration. Their surface morphologies appeared to have a rough surface with characteristic pores, large wrinkles, and cracks as shown in fig. These pores, cracks, and wrinkles may be due to polymeric gel collapsing during the drying process of microspheres.

The in vitro lamivudine release studies were carried out for optimized drumstick mucilage-alginate microspheres of lamivudine and marketed Lamivir Tablet, in the phosphate buffer $\mathrm{pH}$ 7.4. The optimized microspheres showed the release of lamivudine over a period of $12 \mathrm{~h}$ as shown in fig. 12. The release of drug lamivudine from these drumstick mucilage-alginate microspheres was controlled and prolonged in phosphate buffer (pH 7.4), due to the higher swelling rate of these microspheres in phosphate buffer.

Table 5: Curve fitting data of the in vitro release of lamivudine from optimized drumstick mucilage-alginate mucoadhesive microspheres and marketed lamivir tablet

\begin{tabular}{lll}
\hline & Marketed lamivir tablet & F-0pt \\
\hline Zero order & 0.8267 & 0.9427 \\
$1^{\text {st } \text { order }}$ & 0.9978 & 0.9840 \\
Matrix & 0.9890 & 0.9821 \\
Peppas & 0.9809 & 0.9947 \\
Hix. Crow & 0.9845 & 0.9931 \\
$\mathrm{n}$ & 0.5402 & 0.7414 \\
$\mathrm{k}$ & 8.1449 & 15.79 \\
Best fit & First & Peppas \\
\hline
\end{tabular}


The cumulative drug released from the optimized microsphere formulation containing lamivudine in $12 \mathrm{~h}$ was $95.49 \pm 4.05 \%$. The in vitro drug release data from optimized drumstick mucilage-alginate microspheres of lamivudine and marketed tablet Lamivir were evaluated kinetically using various mathematical models like zeroorder, first-order, Higuchi, and Korsmeyer-Peppas. The accuracy and prediction ability of these models were established using the highest regression analysis. The result of the curve fitting $\left(\mathrm{R}^{2}\right)$ into various mathematical models are given in table 5 . The respective $R^{2}$ of optimized drumstick-alginate microspheres of lamivudine were compared, it was found to follow the Korsemeyer-Peppas model $\left(\mathrm{R}^{2}=0.9947\right)$. The best fit of the Korsemeyer-Peppas model shows that the lamivudine release from these optimized drumstick mucilage-alginate microspheres followed the controlled-release pattern. The values of diffusional exponent (n) determined from Korsmeyer-Peppas model was 0.7414 (greater than 0.45), indicating the drug release from optimized formulation of drumstick mucilagealginate microspheres of lamivudine follows, non fickian release mechanism i.e., swelling followed by erosion of polymeric blend, This could be attributed due to polymer dissolution and polymeric chain enlargement or relaxation.

\section{CONCLUSION}

In this investigation, drumstick mucilage-alginate mucoadhesive microspheres of lamivudine were successfully developed and optimized. These developed optimized mucoadhesive microspheres demonstrated high drug encapsulation, sustained drug release profile at a controlled rate. Therefore, these drumstick mucilagealginate mucoadhesive microspheres of lamivudine were found suitable for prolonged systemic absorption of lamivudine through sustained drug release, resulting in improved patient compliance. Moreover, the technique for the preparation of these microspheres was found simple, economical, and consistent.

\section{ACKNOWLEDGMENT}

The authors are grateful to principal and management of V. L. College of Pharmacy, Raichur and KCT College of Pharmacy Gulbarga for the smooth conduct of research experiments.

\section{AUTHORS CONTRIBUTIONS}

All the author have contributed equally

\section{CONFLICT OF INTERESTS}

\section{Declare none}

\section{REFERENCES}

1. Hardenia A, Gupta AK. Development and optimization of gastroretentive mucoadhesive microspheres using $3^{3}$ factorial design. Int J Pharm Sci Res 2016;7:2020-30.

2. Gedam S, Jadhav P, Talele S, Jadhav A. Effect of crosslinking agent on the development of gastroretentive mucoadhesive microspheres of risedronate sodium. Int J Appl Pharm 2018;10:133-40.

3. Panda S, Pattnaik S, Maharana L, Botta GB, Mohapatra P. Formulation and evaluation of zidovudine loaded olibanum resin microcapsules: exploring the use of natural resins as biodegradable polymeric materials for controlled release. Asian J Pharm Clin Res 2013;6:191-6.

4. Yoo SH, Song YB, Chang PS, Lee HG. Microencapsulation of $\alpha$ tocopherol using sodium alginate and its controlled release properties. Int J Biol Macromol 2006;38:25-30.

5. Sriamornsak P, Sungthongjeen S. Modification of theophylline release with alginate gel formed in hard capsules. AAPS Pharm Sci Tech 2007;8:E1-8.

6. Malakar J, Nayak Ak, Pal D. Development of cloxacillin loaded multiple-unit alginate-based floating system by an emulsiongelation method. Int J Biol Macromol 2012;50:138-47.

7. Nayak AK, Khatua S, Hasnain MS, Sen KK. Development of alginate-PVP K30 microbeads for controlled diclofenac sodium delivery using central composite design. DARU J Pharm Sci 2011;19:356-66.

8. Han J, Zhou Z, Yin R, Yang D, JNie J. Alginate chitosan/hydroxyapatite polyelectrolyte complex porous scaffolds: preparation and characterization. Int J Biol Macromol 2010;46:199-205.

9. Patel YL, Sher P, Pawar AP. The effect of drug concentration and curing time on processing and properties of calcium alginate beads containing metronidazole by response surface methodology. AAPS Pharm Sci Tech 2006; 7:E24-30.

10. Pal D, Nayak AK. Development, optimization, and antidiabetic activity of gliclazide-loaded alginate-methyl cellulose mucoadhesive microcapsules. AAPS Pharm Sci Tech 2011; 12:1431-41.

11. Llanes F, Ryan DH, Marchessault RH. Magnetic nanostructured composites using alginates of different $\mathrm{M} /$ Gratios as a polymeric matrix. Int J Biol Macromol 2000;27:35-40.

12. Pal D, Nayak Ak. Novel tamarind seed polysaccharide alginate mucoadhesive microspheres for oral gliclazide delivery: in vitro-in vivo evaluation. Drug Delivery 2012;19:123-31.

13. Borra SP, Eswaraiah MC, Reddy GK. Evaluation of different synthetic and natural polymers as a protective layer on highly soluble and high dose drug metoprolol succinate for manufacturing of control release multi-unit pellets tablets. Int J Appl Pharm 2018;10:69-76.

14. Panda D, Swain S, Gupta R, S Si, Kanungo SK. Preparation and evaluation of gels from gum of Moringa oleifera. Indian J Pharm Sci 2006;68:777-80.

15. Panda D, Choudhury NSK, Yedukondalu M, S Si, Gupta R. Evaluation of gum of Moringa oleifera as a binder and release retardant in tablet formulation. Indian J Pharm Sci 2008;70:614-8.

16. Katlama C, Valantin MA, Matheron S, Coutellier A, Calvez V, Diane D, et al. Efficacy and tolerability of stavudine plus lamivudine in treatment-naive and treatment-experienced patients with HIV-1 infection. Ann Intern Med 1998;129:52531.

17. Princely S, Saleem Basha N, Nandhakumar S, Dhanaraju MD. Controlled delivery of antiretroviral drug-loaded cross-linked microspheres by ionic gelation method. Asian J Pharm Clin Res 2016;9:264-71.

18. Furman PA, Fyfe JA, St Clair MH, Richards CA, Spector T. Phosphorylation of $3^{\prime}$-azido- $3^{\prime}$-eoxythymidine and selective interaction of the $5^{\prime}$-triphosphate with human immunodeficiency virus reverse transcriptase. Proc Natl Acad Sci USA 1986;83:8333-7.

19. Moore KH, Barrett JE, Shaw S, Pakes GE, Churchus R, Kapoor A, et al. The pharmacokinetics of lamivudine phosphorylation in peripheral blood mononuclear cells from patients infected with HIV-1. AIDS 1999;13:2239-50.

20. Becher F, Landman R, Mboup S, Kane CN, Canestri A, Liegeois F, et al. Monitoring of didanosine and stavudine intracellular trisphosphorylated anabolite concentrations in HIV-infected patients. AIDS 2004;18:181-7.

21. Himadrisen, Surva Kumar J. Long-acting composition containing zidovudine and lamivudine. US patent publication US20050175694A1; 2005. p. 1-32.

22. Lewis GA, Matieu D, Phan-Tan-Lu R. Pharmaceutical Experiment Design, Marcel Dekker, New York, NY, USA; 1999.

23. Singh B, Kapil R, Nandi M, Ahuja N. Developing oral drug delivery systems using formulation by design: vital precepts retrospect and prospects. Expert Opin Drug Delivery 2011; 8:1341-60.

24. Singh B, Garg B, Chaturvedi SC, Arora S, Mandsaurwale R, Kapil $\mathrm{R}$, et al. Formulation development of gastroretentive tablets of lamivudine using floating bioadhesive potential of optimized polymer blends. J Pharm Pharmacol 2012;64:654-69.

25. Singh B, Kumar R, Ahuja N. Optimizing drug delivery systems using systematic "design of experiments", part I: fundamental aspects. Crit Rev Ther Drug Carrier Syst 2005;22:27-105.

26. Singh B, Dahiya M, Saharan V, Ahuja N. Optimizing drug delivery systems using systematic "design of experiments", part II: retrospect and prospects. Crit Rev Ther Drug Carrier Syst 2005;22:215-94.

27. Joshi SA, Chavhan SS, Sawant KK. Rivastigmine loaded PLGA and PBCA nanoparticles: preparation, optimization, and characterization, in vitro and pharmacodynamic studies. Eur J Pharm Biopharm 2010;76:189-99. 
28. Ashish, Singh RB. Nature of gum polysaccharide extracted from Moringa oleifera Lam. (Sainjna) plant. Adv Appl Sci Res 2014;5:1-3.

29. Chin CY, Jalil J, Ng PY, Ng SF. Development and formulation of Moringa oleifera standardised leaf extract film dressing for wound healing application. J Etnopharmacol 2018;212:188-199.

30. Prajapati SK, Tripathi P, Ubaidulla U, Anand V. Design and development of gliclazide mucoadhesive microcapsules: in vitro and in vivo evaluation. AAPS Pharm Sci Tech 2008;9:224-30.

31. Nayak AK, Pal D. Development of pH-sensitive tamarind seed polysaccharide-alginate composite beads for controlled diclofenac sodium delivery using response surface methodology. Int J Biol Macromol 2011;49:784-93.

32. Shaji J, Shah A. Optimization of tenoxicam loaded niosomes using quadratic design. Int J Curr Pharm Res 2016;8:62-7. 